Abstract

\title{
Super-Sweet Purple Sweetcorn: Breaking the Genetic Link ${ }^{\dagger}$
}

\author{
Apurba Anirban * and Tim O'Hare * \\ Queensland Alliance for Agriculture and Food Innovation (QAAFI), The University of Queensland, St Lucia, \\ Queensland 4072, Australia \\ * Correspondence: apurba.anirban@gmail.com (A.A.); t.ohare@uq.edu.au (T.O.) \\ + Presented at the third International Tropical Agriculture Conference (TROPAG 2019), Brisbane, Australia, \\ 11-13 November 2019.
}

Published: 29 March 2020

\begin{abstract}
Purple-pericarp supersweet sweetcorn currently does not exist as a horticultural product. Purple pericarp comprises the outer layers of the kernel, with the purple pigment being produced by anthocyanin. Unlike the aleurone layer which can also be pigmented, the pericarp is maternal tissue. Although standard purple sweetcorn based on mutations such as sugary1 (su1) and sugary enhancer (se1) are in existence, the development of purple supersweet sweetcorn based on the widely used shrunken2 (sh2) gene mutation is much more challenging. This is because there is an extremely close genetic linkage between the supersweet shrunken-2 mutation and the anthocyanin biosynthesis gene, anthocyaninless- 1 (a1). As distance between these two genes is only $0.1 \mathrm{cM}$, the development of purple supersweet sweetcorn depends on breaking this close genetic link, which occurs at a very low frequency of 1 in 1000 meiotic crossovers. To make this possible, we crossed a white supersweet variety (a1a1sh2sh2) with a purple-pericarp Peruvian maize (A1A1Sh2Sh2) to obtain an initial heterozygous hybrid (A1a1Sh2sh2). The hybrid seed was sown and subsequently self-pollinated to produce seed segregating for the double recessive homozygote, sh2sh2 (1 in 4). These kernels present a visually distinctive phenotype, characterised by the seed's shrunken appearance. Approximately $2760 \operatorname{sh} 2 \mathrm{sh} 2$ seeds were separated and resown. Due to the low frequency of linkage breakage, the majority of these plants ( $99.9 \%)$ produced supersweet white cobs (a1a1sh2sh2). Three plants (0.1\%) however, produced supersweet purple cobs (A1a1sh2sh2), due to a single low-frequency linkage break. These cobs will form the basis for a purple-pericarp supersweet sweetcorn breeding program.
\end{abstract}

Keywords: purple pericarp; anthocyanin; shrunken2, genetic linkage; meiotic crossover

Funding: This research was funded in part by Hort Innovation, as part of 'Naturally Nutritious' project (HN15001).

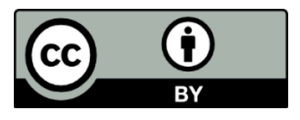

(C) 2020 by the authors. Licensee MDPI, Basel, Switzerland. This article is an open access article distributed under the terms and conditions of the Creative Commons Attribution (CC BY) license (http://creativecommons.org/licenses/by/4.0/). 